\title{
Heteroepitaxial subsurface growth mode resulting in interlayer mixing
}

Murray, P.W.; Thorshaug, S.; Stensgaard, I.; Besenbacher, Flemming; Lægsgaard, E.; Ruban, Andrei; Jacobsen, Karsten Wedel; Kopidakis, Georgios; Skriver, Hans Lomholt

Published in:

Physical Review B

Link to article, DOI:

10.1103/PhysRevB.55.1380

Publication date:

1997

Document Version

Publisher's PDF, also known as Version of record

Link back to DTU Orbit

Citation (APA):

Murray, P. W., Thorshaug, S., Stensgaard, I., Besenbacher, F., Lægsgaard, E., Ruban, A., Jacobsen, K. W., Kopidakis, G., \& Skriver, H. L. (1997). Heteroepitaxial subsurface growth mode resulting in interlayer mixing. Physical Review B, 55(3), 1380-1383. https://doi.org/10.1103/PhysRevB.55.1380

\section{General rights}

Copyright and moral rights for the publications made accessible in the public portal are retained by the authors and/or other copyright owners and it is a condition of accessing publications that users recognise and abide by the legal requirements associated with these rights.

- Users may download and print one copy of any publication from the public portal for the purpose of private study or research.

- You may not further distribute the material or use it for any profit-making activity or commercial gain

- You may freely distribute the URL identifying the publication in the public portal 


\title{
Heteroepitaxial subsurface growth mode resulting in interlayer mixing
}

\author{
P. W. Murray, S. Thorshaug,* I. Stensgaard, F. Besenbacher, and E. Lægsgaard \\ Center for Atomic-Scale Materials Physics (CAMP) and Institute of Physics and Astronomy, University of Aarhus,
} DK 8000 Aarhus $C$, Denmark

A. V. Ruban, K. W. Jacobsen, G. Kopidakis, and H. L. Skriver

Center for Atomic-Scale Materials Physics (CAMP), Department of Physics, Technical University of Denmark, DK 2800 Lyngby, Denmark

(Received 27 September 1996)

\begin{abstract}
A subsurface growth mode which results in interlayer mixing has been revealed from an interplay between scanning tunneling microscopy and ab initio total-energy calculations for the growth of $\mathrm{Pd}$ on $\mathrm{Cu}(110)$ and $\mathrm{Ag}(110)$ surfaces. On $\mathrm{Cu}(110)$, the Pd initially alloys into the surface layer forming ordered linear -Pd-Cuchains. As the coverage is increased, the - $\mathrm{Pd}-\mathrm{Cu}$ - chains remain at the same level, but become covered, partly by $\mathrm{Cu}$ atoms expelled during alloying, partly by substrate material supplied from steps and terraces. This results in a very rough surface morphology, even at relatively low Pd coverages. Similar structures were observed on $\mathrm{Ag}(110)$. The observed growth mode is expected to apply to other heteroepitaxial systems as well. [S0163-1829(97)01603-2]
\end{abstract}

Over the past few years, there has been a considerable interest in metal-on-metal growth. The application of scanning tunneling microscopy (STM) has given unprecedented insight at the atomic level into many systems which are of interest both from a fundamental point of view and because of the technological relevance of chemical, electronic, and magnetic properties of thin metal films. In many cases, the growth mode and the structures formed are much more complex than originally anticipated based on thermodynamical equilibrium arguments. ${ }^{1}$ Examples include surface-alloy formation in which the deposited metal intermixes with the topmost layer of the substrate rather than forming a simple overlayer structure, ${ }^{2}$ even between metals, which are immiscible in the bulk, ${ }^{3-6}$ and subsurface growth where the deposited metal forms one or more layers underneath the substrate surface. ${ }^{7-10}$ Whereas detailed information at the atomic level has recently become available for surface alloying, such details regarding subsurface growth have remained more elusive.

In this paper, we present detailed STM studies in combination with total-energy calculations which reveal a subsurface growth mechanism. The growth mode will be discussed in relation to results for $\mathrm{Pd}$ on $\mathrm{Cu}(110)$, but results for $\mathrm{Pd}$ on $\operatorname{Ag}(110)$ are presented as well. It is shown that at room temperature (RT), Pd does not penetrate beneath the surface layer, but instead becomes incorporated at subsurface sites through a combination of surface alloying and removal of substrate material from surrounding terraces. This requires more metal atoms to be displaced than Pd atoms deposited, and results in a rough surface morphology even for low $\mathrm{Pd}$ coverages. Based on bulk-alloy data we speculate that, for example, $\mathrm{Pt}$ on $\mathrm{Cu}(110)$ may grow in the same manner, and we expect that the subsurface-growth mode will lead to dramatic differences in the reactivity of the $\mathrm{Pd} / \mathrm{Cu}(110)$ surface relative to the $\mathrm{Pd} / \mathrm{Cu}(100)$ surface on which the $\mathrm{Pd}$ atoms alloy into the first layer. ${ }^{11}$
The STM and sample-preparation procedures used in this study are identical to those used in an earlier growth study. ${ }^{11}$ Palladium evaporation was carried out with the sample at RT by resistively heating a conical $\mathrm{W}$ filament containing a $\mathrm{Pd}$ wire. Coverages of $\mathrm{Pd}$ [with $1 \mathrm{ML}$ defined as the $\mathrm{Cu}(110) / \mathrm{Ag}(110)$ surface-atom density] were determined from in situ Rutherford backscattering spectroscopy and $\mathrm{Au}-$ ger electron spectroscopy. All STM images were recorded at RT in the constant-current mode.

Following deposition of approximately 1-2\% of a ML of $\mathrm{Pd}$ on $\mathrm{Cu}(110)$, atomically resolved images reveal the formation of chains aligned primarily along the close-packed [1 $\overline{1} 0]$ direction, as shown in Fig. 1(a). The periodicity of the protrusions along the chains corresponds to two nearestneighbor distances. The corrugation of the protrusions is consistent with that observed for $\mathrm{Pd}$ on $\mathrm{Cu}(100)$, approximately $0.3 \AA .{ }^{11}$ The chains may also appear as depressions depending on tip conditions. Based on our study of Pd alloying on $\mathrm{Cu}(100),{ }^{11}$ we assign the protrusions in Fig. 1(a) to $\mathrm{Pd}$ atoms alloyed into substitutional sites in the surface layer. The periodicity of the $\mathrm{Pd}$ atoms along the linear chains is identical to that in the $\mathrm{Cu}_{3} \mathrm{Pd}$ bulk-alloy structure. Larger scale images, Fig. 1(b), show that correlated with the Pd deposition, the step edges have become serrated, in contrast to the smooth appearance on the clean surface. Such step roughening has been observed on a number of surfacealloying systems where expelled substrate atoms migrate to nearby steps. ${ }^{9,11,12}$

Further exposure to $\mathrm{Pd}$ results in significant islanding together with the formation of pits, as shown in Fig. 1(c), which corresponds to 0.17 ML Pd coverage. Simultaneously, the linear -Pd-Cu- chains seen in Fig. 1(a) have disappeared. At these coverages, most of the pits can be seen to be eroded areas of an upper terrace, which would be the easiest source of $\mathrm{Cu}$ atoms. ${ }^{13} \mathrm{~A}$ height distribution for an image recorded over a large area with no steps, but for an identical Pd coverage, is shown in Fig. 1(d) which yields the surface areas 

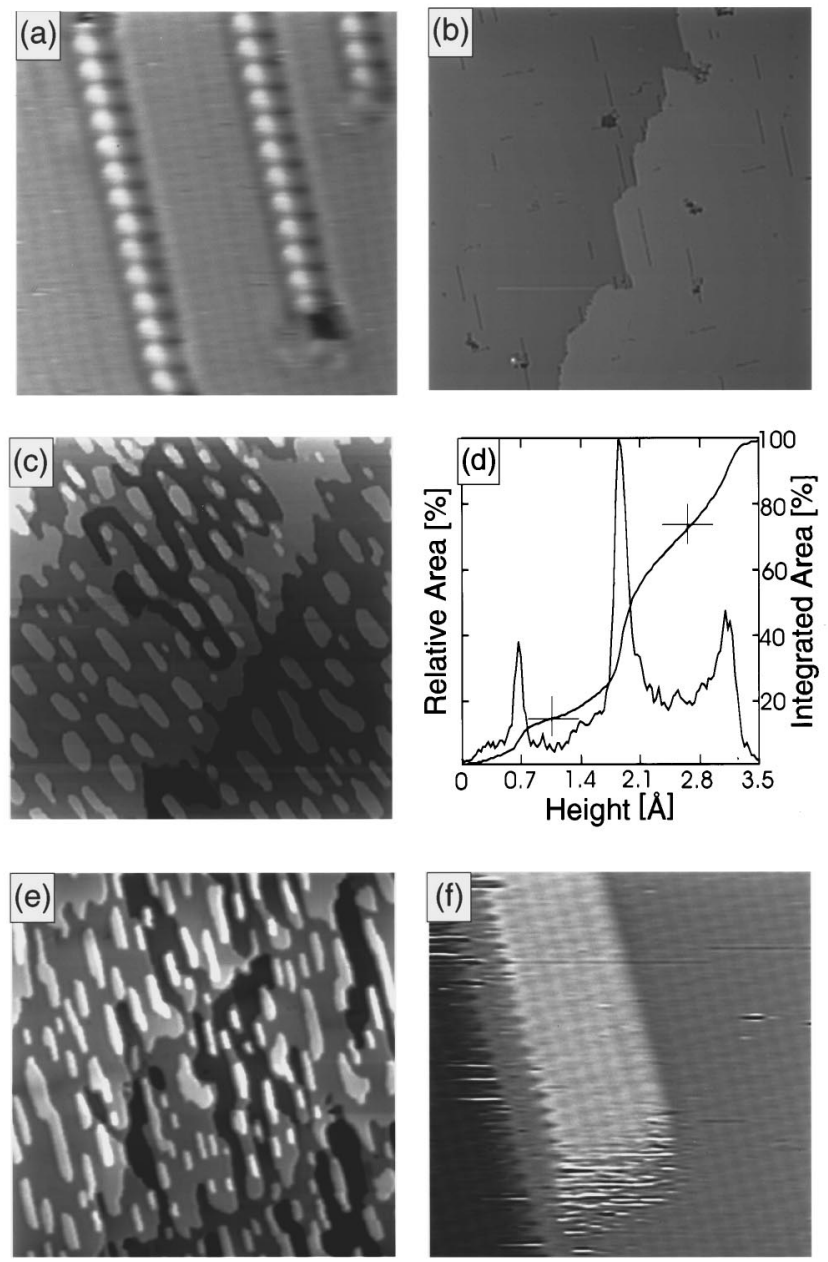

FIG. 1. (a) STM image following deposition of small amounts of $\mathrm{Pd}$ on $\mathrm{Cu}(110)$. Linear chains are observed, which are aligned along the close-packed $[1 \overline{1} 0]$ direction and are ascribed to $\mathrm{Pd}-\mathrm{Cu}$ chains alloyed into the surface $\left(70 \times 70 \AA^{2}\right)$. The apparent asymmetry is ascribed to a tip artifact. (b) Large-area images for the same coverage showing the formation of small islands together with a roughening of the step edges $\left(1030 \times 990 \AA^{2}\right)$. (c) After deposition of $0.17 \mathrm{ML}$ Pd. The island size has increased, and a preferential alignment along the [110] direction is seen. Also the formation of pits is observed $\left(3060 \times 2960 \AA^{2}\right)$. (d) Height distribution corresponding to $0.17 \mathrm{ML}$. The islands (pits) can be seen to occupy approximately $30 \%(15 \%)$ of the surface area. (e) Coverage 0.28 ML Pd. An increase in island and pit density is seen $(1500 \times 1500$ $\AA^{2}$ ). (f) Atomically resolved images of an island showing features consistent with $\mathrm{Cu}(110)$ and no evidence for any Pd structures $\left(81 \times 80 \AA^{2}\right)$.

covered by the islands, the terraces, and the pits. It can be seen that the area covered by the islands is $30 \%$, roughly twice that of the Pd coverage, while the pits more closely match the latter in area $(15 \%)$. Increasing the Pd coverage further to $0.28 \mathrm{ML}$ results in even greater restructuring. Long islands and pits [Fig. 1(e)], predominantly orientated along the close-packed [110] direction, are seen. Neither islands nor pits show any evidence for Pd atoms in the surface layer, and atomically resolved images [Fig. 1(f)] display only features consistent with a bare $\mathrm{Cu}(110)$ surface.

In the case of $\mathrm{Pd}$ deposition on $\mathrm{Ag}(110)$, qualitatively similar island and pit structures are formed as shown in Fig.
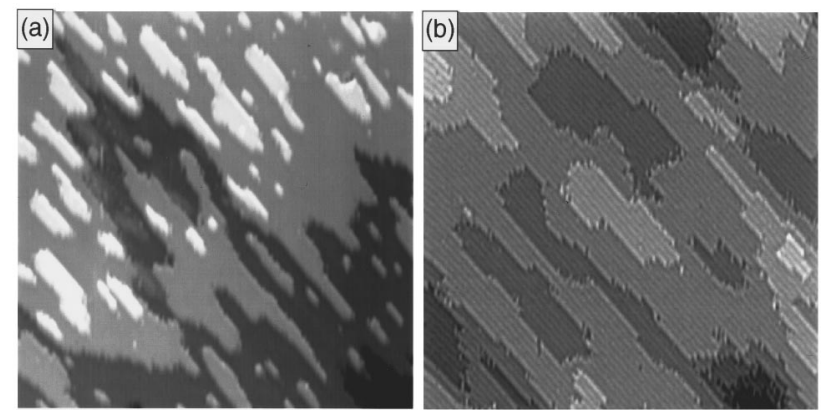

FIG. 2. (a) A STM image recorded after deposition of Pd on a $\mathrm{Ag}(110)$ surface. Structures similar to those seen on $\mathrm{Cu}(110)$ are observed, i.e., formation of islands and pits on the terraces $\left(1000 \times 1000 \AA^{2}\right)$. (b) Higher-resolution image in which the close-packed [110] rows are resolved. Again no evidence for Pd features is observed $\left(300 \times 300 \AA^{2}\right)$.

2, although there is a stronger tendency to form multilayer structures, especially on large terraces. Furthermore, at low coverages, no ordered strings are seen, and as the coverage is increased, many small islands form, as opposed to larger islands observed on $\mathrm{Cu}(110)$ for identical $\mathrm{Pd}$-evaporation conditions. Step heights measured from images recorded on both substrates show that the interlayer spacing between the islands, terraces, and pits is consistent with the values for $\mathrm{Cu}(110) / \mathrm{Ag}(110)$ steps. The assignment of the entire topmost layer to substrate atoms is further confirmed by exposure to oxygen, where $(2 \times 1)$ and $(n \times 1)$ structures form on $\mathrm{Cu}(110)$ and $\operatorname{Ag}(110)$, respectively. There is thus strong experimental evidence that for coverages above $\approx 0.1 \mathrm{ML}$, there is no $\mathrm{Pd}$ in the topmost layer and hence that a more elaborate mechanism is involved than just a simple exchange between $\mathrm{Pd}$ and substrate atoms in the top layer (i.e., surface alloying).

Further experimental observations indicate that the Pd has not diffused into the bulk but must be located subsurface, stabilizing the islands. Within some of the pits, double-layer islands are sometimes observed [see Fig. 1(e)]. These can be rationalized as the top island being located above the $\mathrm{Pd}$ alloyed structures. As more pits are created in these regions, the areas around such Pd structures will be eroded away. However, the $\mathrm{Cu}$-covered $\mathrm{Pd}$ structures themselves will not be eroded as they are already in a stable configuration once the $\mathrm{Pd}$ is subsurface. This leads to double-layer islands. A further indication of the stability of the of the islands is obtained by exposure of the surface to oxygen. If there were no $\mathrm{Pd}$ below the $\mathrm{Cu}$ islands, then one would expect them to be good sources of $\mathrm{Cu}$ atoms required for the formation of -Cu-O- added rows. ${ }^{13}$ Surprisingly, although we did observe the $-\mathrm{Cu}-\mathrm{O}$ - added rows, very little erosion of the islands took place. The $\mathrm{Cu}$ atoms forming the islands are thus much more strongly bound than one would expect if they were located on top of a pure $\mathrm{Cu}$ lattice. Similar features were seen upon exposing the $\mathrm{Pd} / \mathrm{Ag}(110)$ surface to oxygen.

To provide a detailed explanation of the observed phenomena, the surface energies of $\mathrm{Cu}(110)$ and $\mathrm{Ag}(110)$ with $\mathrm{Pd}$ in the first, second, or third layers were calculated by means of the linear muffin-tin orbitals method in conjunction with the coherent potential approximation and Green's function technique. ${ }^{14-16}$ In the present application, a $(2 \times 1)$ unit 

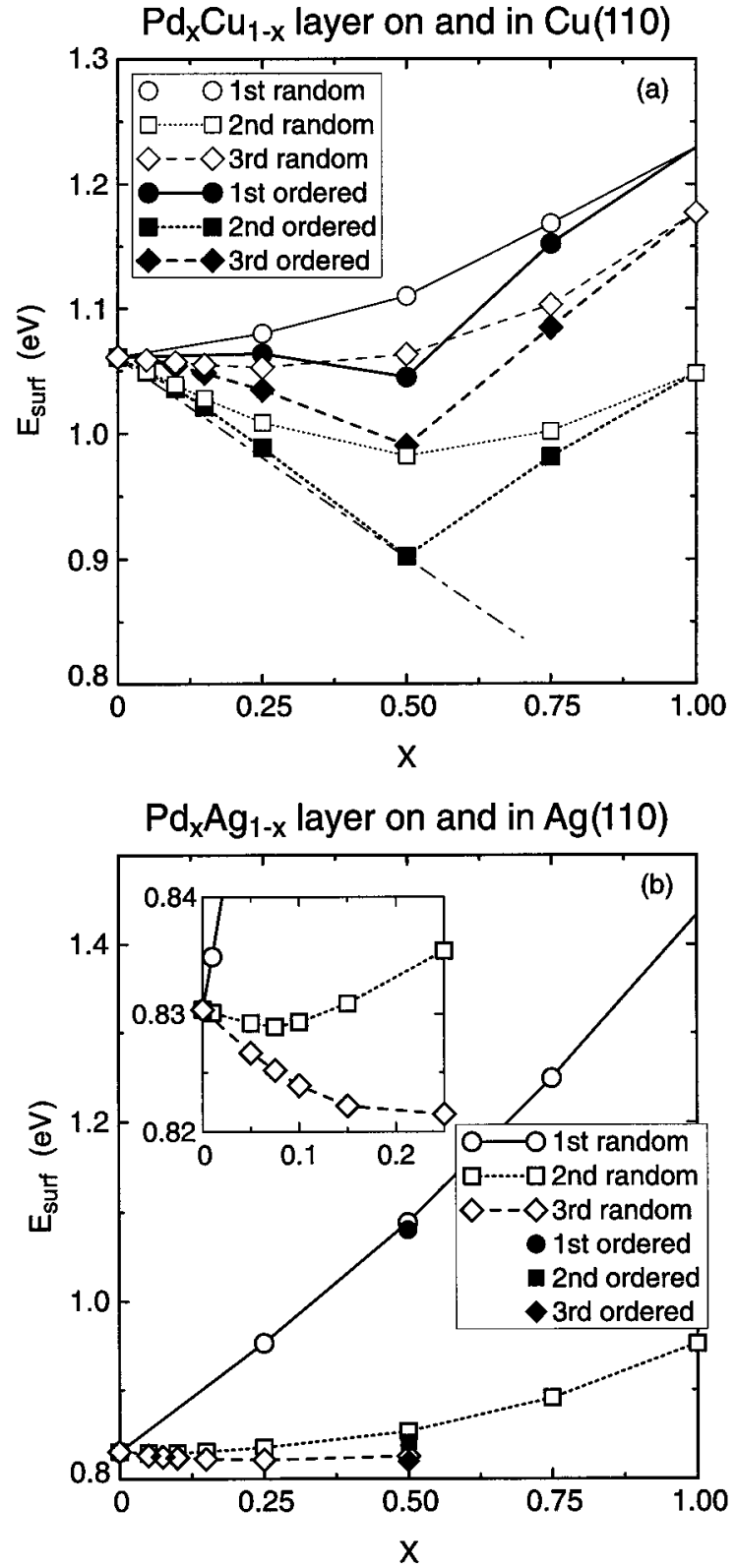

FIG. 3. Calculated surface energies of eight-layer films for random and ordered Pd structures in either the first, second, or third layers of a (a) $\mathrm{Cu}(110)$ and (b) $\mathrm{Ag}(110)$ surface, as a function of the fraction $x$ of $\mathrm{Pd}$.

cell of the fcc(110) surface, consisting of eight layers of atomic spheres and four layers of vacuum spheres, was treated self-consistently. The screened impurity model has been used for the Madelung potential and energy of completely random and partially ordered alloys with $\beta=0.55$ in both cases. ${ }^{17,18}$ Other details of the calculational method are described in Refs. 14,15 .

In Fig. 3(a), the surface energies of ordered and random alloys in the first, second, or third layer of an otherwise pure $\mathrm{Cu}(110)$ surface are shown. For the ordered alloys, we have considered a $(2 \times 1) \mathrm{Pd}_{x} \mathrm{Cu}_{1-x}$ alloy with $-\mathrm{Pd}-\mathrm{Cu}$ - chains along the [110] direction. There is a complete order for $x=0.5$ and a partial order for $x \neq 0.5$. We have not considered other possible ordered structures in the layer since, according to our estimate based on the Connolly-Williams method $^{19}$ as well as the results of Lu et al. ${ }^{20}$ the nearestneighbor interaction is dominating in the system, and therefore the formation of other types of ordered structures on the surface is hardly possible. Figure 3(a) shows that in the first, second, and third layer, there is a gain in energy if the Pd is ordered. However, the minimum-energy configuration is obtained when the ordered Pd structures are located in the second layer.

To determine the most stable structure for a Pd coverage less than $0.5 \mathrm{ML}$, it is noted that all other energy points in Fig. 3(a) lie above the dot-dash line between the points corresponding to the surface energy of pure $\mathrm{Cu}(110)$ and the surface energy of the completely ordered alloy in the second layer (full square at $x=0.5$ ). This means that for $\theta_{\mathrm{Pd}}<0.5$, the system will phase separate into regions of pure $\mathrm{Cu}(110)$ surface and regions (islands) with an ordered $(2 \times 1) \mathrm{PdCu}$ alloy in the second layer, covered by a pure $\mathrm{Cu}$ layer. The island structure is thus identical to the equilibrium structure of a $\mathrm{Cu}_{3} \mathrm{Pd}(110)$ surface which is also terminated by a $\mathrm{Cu}$ layer.

These results explain the most important features observed in the experiment: Formation of the ordered -Pd-Cuchains and ordered $\mathrm{PdCu}$ islands, as well as their preference to be covered by a monolayer of $\mathrm{Cu}$. The results also provide an understanding of the $2: 1$ ratio of the island area to $\mathrm{Pd}$ coverage found on the basis of height histograms such as that in Fig. 1(d). However, in the alloying process, only half the $\mathrm{Cu}$ atoms required to cover the $(2 \times 1)$ alloy would be squeezed out by $\mathrm{Pd}$ atoms. Thus the remaining $\mathrm{Cu}$ must be supplied from the substrate. This is consistent with the formation of pits extending into upper terraces, as shown in Fig. 1(c). Therefore, although the Pd is located in the second layer, there is no actual diffusion or movement of Pd beyond the surface layer. Rather, the process involves displacement of substrate material to cover the Pd.

The existence of the stable, ordered - $\mathrm{Pd}-\mathrm{Cu}$ - chains on $\mathrm{Cu}(110)$ at very low $\theta_{\mathrm{Pd}}$ can be understood as well. Covering a $\mathrm{PdCu}$ island with substrate material leads to the creation of steps along the perimeter of the island, i.e., to the formation of linear defects of positive energy. For a single -Pd-Cuchain, the energy gained by covering the chain with $\mathrm{Cu}$ atoms does not outweigh the energy cost of creating the steps. However, as the Pd coverage increases and $\mathrm{PdCu}$ islands start to form, the perimeter:area ratio drops dramatically and hence the energy balance changes in favor of forming $\mathrm{PdCu}$ islands capped with a monolayer of pure $\mathrm{Cu}$.

For $\mathrm{Pd} / \mathrm{Ag}(110)$ [Fig. 3(b)], the ordering energy is much smaller than in the case of $\mathrm{Cu}(110)$. This may explain why no ordered strings are observed in the STM images of $\mathrm{Ag}(110)$ at low Pd coverages. Alternatively, the much lower surface energy of $\mathrm{Ag}$ compared to $\mathrm{Cu}$ (see Fig. 3 at $x=0$ ) could make the initiation of subsurface growth less dependent on a critical coverage. It is noted from Fig. 3(b) that a $\mathrm{Pd}$ position in the surface layer is again very unfavorable compared to the second layer, and that there is a slight energy to be gained even at low Pd coverages by letting the Pd atoms move deeper into the surface. However, two observations point to a near-surface structure similar to that found for $\mathrm{Pd}$ on $\mathrm{Cu}(110)$. First, we find that the island:pit:Pd ratios are similar on $\mathrm{Ag}(110)$ and $\mathrm{Cu}(110)$. Second, the theoretical calculations show that the effective pair interactions increase 
with Ag concentration, making the formation of the ordered -Pd-Ag- chains in the [1힐 direction quite possible for very small concentrations of Ag. It is thus very likely that the observed Ag islands are stabilized by subsurface -Pd-Agstructures equivalent to the $\mathrm{Cu}$ case, and that a transition to a lower-energy state with the Ag atoms deeper in surface is kinetically hindered at RT.

The formation of islands and pits has also been observed for $\mathrm{Au}$ on $\mathrm{Ag}(110)$ by Hirschorn et al. ${ }^{9}$ Again the $\mathrm{Au}$ is reported to grow in a subsurface mode. However, in that case a burrowing mechanism was proposed for Au going subsurface. Furthermore, statistics regarding the island:pit ratio as a function of coverage, as well as atomic-scale resolved images were unavailable. In the $\mathrm{Au} / \mathrm{Ag}$ case, the pits were seen to preferentially nucleate on the lower side of step edges, resulting in double steps, as opposed to the observations in the present study. This suggests that the mechanisms involved may differ considerably between the two systems.

In summary, we have reported a subsurface growth mode, observed for the growth of $\mathrm{Pd}$ on $\mathrm{Cu}(110)$ and $\mathrm{Ag}(110)$ sur-

*Also at Department of Physics, The Norwegian Institute of Technology, University of Trondheim, N-7034 Trondheim, Norway.

${ }^{1}$ E. Bauer, Z. Kristallogr. 110, 372 (1958).

${ }^{2}$ U. Bardi, Rep. Prog. Phys. 57, 939 (1994).

${ }^{3}$ L. Pleth Nielsen, F. Besenbacher, I. Stensgaard, and E. Lægsgaard, Phys. Rev. Lett. 71, 754 (1993).

${ }^{4}$ P. Hu, A. Wander, L. M. Delagarza, M. P. Bessent, and D. A. King, Surf. Sci. 293, L917 (1993).

${ }^{5}$ C. Nagl, E. Platzgummer, O. Haller, M. Schmid, and P. Varga, Surf. Sci. 331-333, 831 (1995).

${ }^{6}$ P. T. Sprunger, E. Lægsgaard, and F. Besenbacher, Phys. Rev. B 54, 8163 (1996).

${ }^{7}$ C. Nagl, E. Platzgummer, M. Schmid, P. Varga, S. Speller, and W. Heiland, Phys. Rev. Lett. 75, 2976 (1995).

${ }^{8}$ S. Rousset, S. Chiang, D. E. Fowler, and D. D. Chambliss, Phys. Rev. Lett. 69, 3200 (1992).

${ }^{9}$ E. Hirschorn, D. S. Lin, E. D. Hansen, and T.-C. Chiang, Surf. Sci. 323, L299 (1995).

${ }^{10}$ A. K. Schmid, D. Atlan, H. Itoh, B. Heinrich, T. Ichinokawa, and J. Kirschner, Phys. Rev. B 48, 2855 (1993). faces. The STM data have indicated that on $\mathrm{Cu}(110)$, the $\mathrm{Pd}$ initially alloys into the surface, forming ordered linear - $\mathrm{Pd}$ $\mathrm{Cu}$ - chains which then become covered, partly by the substrate atoms squeezed out during surface alloying, partly by substrate atoms removed from terraces, as opposed to a direct atomic burrowing into the subsurface positions. The composition and stability of the observed structures have been confirmed based on ab initio total-energy calculations. We have observed a qualitatively similar growth mode for Pd on $\mathrm{Ag}(110)$. Based on similarities in bulk-alloy data, such general trends may be applicable to other systems as well, such as $\mathrm{Pt}$ on $\mathrm{Cu}(110)$.

We would like to acknowledge financial support from an EU network on "Bond Making and Breaking at Surfaces,", the Danish Science Research Councils via the "Center for Surface Reactivity," and the "Center for Atomic-scale Materials Physics", (CAMP), sponsored by the Danish National Research Foundation.

${ }^{11}$ P. W. Murray, I. Stensgaard, E. Lægsgaard, and F. Besenbacher, Phys. Rev. B 52, R14 404 (1995).

${ }^{12}$ D. D. Chambliss and S. Chiang, Surf. Sci. 264, L187 (1992).

${ }^{13}$ F. Jensen, F. Besenbacher, E. Lægsgaard, and I. Stensgaard, Phys. Rev. B 41, 10233 (1990).

${ }^{14}$ H. L. Skriver and N. M. Rosengaard, Phys. Rev. B 43, 9538 (1991).

${ }^{15}$ A. I. Abrikosov and H. L. Skriver, Phys. Rev. B 47, 16532 (1993).

${ }^{16}$ A. V. Ruban, I. A. Abrikosov, D. Ya Kats, D. Gorelikov, K. Jacobsen, and H. L. Skriver, Phys. Rev. B 49, 11383 (1994).

${ }^{17}$ I. A. Abrikosov, A. V. Ruban, H. L. Skriver, and B. Johansson, Phys. Rev. B 50, 2039 (1994).

${ }^{18}$ A. V. Ruban, I. A. Abrikosov, and H. L. Skriver, Phys. Rev. B 51, 12958 (1995).

${ }^{19}$ J. W. D. Connolly and A. R. Williams, Phys. Rev. B 27, 5169 (1983).

${ }^{20}$ Z. W. Lu, S.-H. Wei, A. Zunger, S. Frota-Pessoa, and L. G. Ferreira, Phys. Rev. B 44, 512 (1991). 